Revista Eletrônica de Ciência Administrativa (RECADM) - ISSN 1677-7387

Faculdade Cenecista de Campo Largo - Coordenação do Curso de Administração

v. 1, n. 2, nov./2003 - http://revistas.facecla.com.br/index.php/recadm/

\title{
0 processo de introdução da maquinaria na indústria fabril e o trabalhador
}

Alexandre Shigunov Neto ${ }^{1} \&$ Renata Messias Gomes ${ }^{2}$

\section{Considerações iniciais}

O objetivo deste texto é analisar as implicações que a introdução da maquinaria trouxe para os trabalhadores das fábricas, tomando como ponto de partida o período inicial da Revolução Industrial. Tomando como hipótese de trabalho que a maquinaria em si, como instrumento auxiliar do progresso, é benéfica para a sociedade e, até mesmo, para o trabalhador, no entanto, a aplicação dada pelo capitalista é que poderá ser prejudicial para os mesmos, em especial para o trabalhador e suas condições de trabalho.

Ao analisar-se a introdução da maquinaria nas indústrias fabris levar-se-á em conta três variáveis, que estão diretamente envolvidas nesse processo histórico: a divisão do trabalho; o papel da escola nesse período; e a questão da dicotomia entre saber $X$ fazer, entre teoria $X$ prática.

A análise da Revolução Industrial é essencial no entendimento da evolução do processo produtivo, das condições de trabalho e do próprio trabalhador, pois foi nesse período que ocorreram diversas transformações que tiveram impacto direta e/ou indiretamente sobre a vida da sociedade e do homem, enquanto membro da mesma. A principal delas foi a divisão do trabalho no processo produtivo, implicando inicialmente, a perda do controle por parte do trabalhador do produto de seu trabalho, e posteriormente, do controle sobre o processo de seu trabalho.

O período denominado de Revolução Industrial pode ser considerado como um importante momento histórico da humanidade, caracterizado basicamente pela transição de uma sociedade fundamentada em uma economia agrária para uma nova sociedade, pautada agora nos princípios de uma economia capitalista e industrial. Poderíamos dizer, também que, a Revolução Industrial é o momento histórico que presencia a implantação do sistema de produção capitalista.

A Revolução Industrial implicou em uma transformação social, econômica, política e cultural radical e díspar, mas que ocorreu gradativamente na vida humana, foi essencialmente uma transformação no modelo de produção. Teve seu início no século XVIII na Grã-Bretanha e se espalhou posteriormente por toda a Europa. Cronologicamente pode-se dividir a Revolução Industrial em duas fases: a primeira fase, que perdurou aproximadamente entre 1750 e 1860 - e foi impulsionada pelo setor têxtil; a segunda fase durou até aproximadamente 1945. Marca uma nova fase do industrialismo, que proporcionaria alicerces muito mais firmes para o crescimento econômico e foi baseada nas indústrias de bens de capital, no carvão, no ferro e no aço.

A Revolução Industrial assinala

a mais radical transformação da vida humana já registrada em documentos escritos. Durante um breve período ela coincidiu com a história de um único país, a Grã-Bretanha. Assim, toda uma economia mundial foi edificada com base na Grã-Bretanha, ou antes, em torno desse país, que por isso ascendeu temporariamente a uma posição de influência e poder mundiais sem paralelo na história de qualquer país com as suas dimensões relativas, antes ou desde então, e que provavelmente não será igualada por qualquer Estado no futuro previsível. (Hobsbawm,1979,p.13)

A compreensão sobre a origem da Revolução Industrial não é tão simples quanto possa parecer, pois apesar de haver consenso sobre o país onde teve origem, a GrãBretanha, não há uma posição muito clara sobre as causas que levaram a Grã-Bretanha a

\footnotetext{
1 Administrador. Mestre em Educação. Coordenador do Curso de Administração da Faculdade Cenecista Presidente Kennedy de Campo Largo-Paraná. Coordenador do Núcleo de Estudos Pedagógicos e Administrativos (NEPA). Email: shigunov@presidentekennedy.br

${ }^{2}$ Engenheira Química formada pela Universidade Estadual de Maringá (UEM) e Especialista em Gestão da Qualidade em Alimentos. Email: renatamessias@ibest.com.br
} 
ter sido considera a precursora desse movimento. Contudo, pode-se supor que, as condições que proporcionaram a revolução e a transformação no modo de produção inglês são dividas em três, sendo importante destacar que ambas foram essenciais, cada uma a seu modo, para a consolidação de tal processo: a importância do mercado interno, que era o maior mercado consumidor dos produtos do país; o mercado externo ou de exportação, que era muito mais dinâmico e seguro; e o papel do governo.

(...) no contexto desse quadro geral, a história da Grã-Bretanha é a história da primeira fase da industrialização mundial - a Revolução Industrial, a formação de uma única economia mundial liberal e a penetração e conquista finais do mundo subdesenvolvido e não-capitalista pelo capitalista, Seu triunfo foi a vitória do pioneiro dessa fase da história; seu declínio, a decadência de todo um sistema econômico mundial. (Hobsbawm,1979,p.294)

As transformações ocorridas na vida humana durante esse período, e em especial na vida do trabalhador, foram inúmeras e até certo ponto, um tanto quanto radicais. Pois implicaram em mudanças profundas nos padrões e nos valores aceitos, na cultura e na própria sobrevivência dos homens da época. Assim, encontramos nesse período um contra-senso, pois em termos econômicos, o século XIX foi uma época marcada por conquistas e desenvolvimento, contudo, em termos sociais, foi um período de grandes desigualdades sociais, pobreza e "degradação" do trabalho e do próprio trabalhador.

As características desse novo processo de produção são basicamente: o surgimento da fábrica; a extensão da divisão do trabalho; a adaptação dos trabalhadores à máquina; a importância econômica do capital para financiar a produção e equipamentos.

O surgimento e a consolidação das unidades fabris não foi como se pode pensar um processo rápido e sem implicações para a sociedade e para o trabalhador, muito pelo contrário, foi um processo muito lento, desgastante e que em muitos casos acabou utilizando-se do artifício da coerção e da violência. No entanto, ao longo do tempo alguns problemas foram sendo solucionadas, em prol dos objetivos do capitalista, tais como: a questão da indisciplina dos trabalhadores; a dissonância entre os objetivos dos trabalhadores e do capitalista; a questão da preguiça dos trabalhadores, assim definida pelo capital; a questão do lazer dos trabalhadores; a questão das invenções e as mudanças tecnológicas; a questão do controle dos trabalhadores; a fiscalização e a necessidade de disciplina dos trabalhadores; a formulação de leis contra os trabalhadores para trabalharem mais. Assim, o surgimento da fábrica é uma transformação radical no processo de produção e no próprio modo de viver dos trabalhadores.

A fábrica pode ser definida como o local onde vários trabalhadores exerciam suas funções, ou seja, é a concentração dos trabalhadores em um único local. Desse modo, é nesse momento que começa a surgir um conceito "novo" - na realidade não tão novo, pois já era utilizado nas sociedades antigas, mas que renasce com uma nova conotação que futuramente será muito utilizado pelo capital, o controle sobre o processo produtivo.

A extensão da divisão do trabalho corresponde ao processo de intensificação e aprimoramento da divisão do trabalho dentro das instituições fabris, ou popularmente denominadas de fábricas. Assim, o trabalhador e seu trabalho vivem em função das máquinas da fábrica. O mais

antigo princípio inovador do modo capitalista de produção foi a divisão manufatureira do trabalho, e de uma forma ou de outra a divisão do trabalho permaneceu o princípio fundamental da organização industrial. A divisão do trabalho na indústria capitalista não é de modo algum idêntica ao fenômeno da distribuição de tarefas, ofícios ou especialidades da produção através da sociedade, porquanto, embora todas as sociedades conhecidas tenham dividido seu trabalho em especialidades produtivas, nenhuma sociedade antes do capitalismo subdividiu sistematicamente 0 trabalho de cada especialidade produtiva em operações limitadas. Esta forma de divisão do trabalho torna-se generalizada apenas com o capitalismo. (Braverman,1977,p.70)

A adaptação dos trabalhadores à máquina é característica fundamental desse novo processo produtivo, pois com os novos valores do sistema capitalista agora vigentes, sua 
preocupação obstinada em acumular cada vez maior quantidade de capital e obter sempre uma maior produtividade, o homem deixa de ser fator essencial no processo produtivo para ser apenas um instrumento da máquina, ou seja, a máquina é que passa a ser fundamental no processo.

Essa nova concepção capitalista de produção requisitará um maior investimento no processo produtivo, com a aquisição de novas maquinarias e a melhoria do processo produtivo.

Não obstante, as transformações ocorridas no processo produtivo, essa nova fase da história da humanidade exigiu novas estruturas que atendessem as também novas necessidades da sociedade, em específico às do capital, necessidades estas relacionadas com um novo modelo de trabalhador.

Coube, dessa maneira, a escola esta função de formação de mão-de-obra qualificada para atender aos interesses capitalistas e de uma sociedade operária em formação.

\section{A divisão do trabalho e o papel da escola}

O trabalho humano evoluiu ao longo dos anos acompanhando as necessidades humanas e as transformações ocorridas nos processos de produção.

Para compreensão do estudo, convencionou-se apresentar a concepção de trabalho, enquanto necessário para a reprodução humana, em três modelos simplificados de sociedades distintas: a sociedade primitiva e de subsistência; a sociedade préindustrial; a sociedade industrial. Entretanto, nossa análise terá como foco o trabalho no período industrial.

De acordo com Mariano Fernández Enguita (1989), em sua análise sobre as influências positivas e negativas do capitalismo e da industrialização, é necessário compreender além daquelas específicas para a sociedade, pois

esses são desvios com relação ao que é aqui o problema principal: as mudanças radicais na função e nas características do trabalho e de seu lugar na vida das pessoas. É um caminho muito longo e tortuoso aquele que vai desde a produção para a subsistência até o trabalho assalariado na sociedade industrial - ou, se se prefere, pós-industrial, o que para o caso dá no mesmo -, e podemos começar a fazer uma idéia de suas dimensões e obstáculos se pensarmos nas diferenças entre os extremos percorridos. (p. 6)

$\mathrm{Na}$ sociedade primitiva ou de subsistência o homem e a sociedade apenas produzem para satisfação imediata de suas necessidades; não existe ainda a necessidade de produzir uma quantidade maior para troca por outros bens; o homem possui o completo domínio do processo de trabalho e do produto produzido; os instrumentos utilizados na produção dos bens são rudimentares; não havia a distinção clara entre o tempo destinado ao trabalho e tempo destinado ao ócio; a sociedade e o homem, em específico, são auto-suficientes e independentes; e a divisão do trabalho é simples, ficando apenas entre a repartição de tarefas entre homens e mulheres.

Nas sociedades pré-industriais o homem e a sociedade começam a se preocupar em produzir uma quantidade maior de bens para satisfação das necessidades imediatas, futuras; a troca surge como um princípio e para a troca por outros bens; o homem perde 0 controle sobre o produto do trabalho mas, ainda não, sobre o processo de trabalho; já existe uma clara distinção entre o tempo destinado ao ócio e ao trabalho; os instrumentos utilizados na produção dos bens já são complexos e exigem maiores técnicas; a sociedade e o homem, em específico, já não são tão auto-suficientes, tornan-se dependentes, ou seja, apenas possuem uma independência relativa; a divisão do trabalho, como se conhece hoje, começa a surgir no processo produtivo. Por isso

a passagem da produção para o mercado ao trabalho assalariado, independentemente das diversas subformas que possam adotar um e outro, representa a passagem da independência à dependência, ou de depender tãosomente de forças impessoais como são ou parecem ser as do mercado, embora 
estejam mediadas pelas pessoas, a ver-se inserido em certas relações de dependência pessoal, embora estejam mediadas pelas coisas; a passagem da elaboração completa do produto, que pode ser a base do orgulho profissional, à contribuição parcial e fragmentária, a qual pode trazer tão-somente a sensação de insignificância; a passagem, enfim, do domínio do processo de trabalho em sua totalidade à inserção no seio de uma organização estruturada em torno de um poder hierárquico e alheio à pessoa do trabalhador. (Enguita,1989,p.16)

Já na sociedade industrial, existe uma inversão completa dos valores e da lógica que determinam a sociedade, o homem perde o completo domínio do processo de trabalho e do próprio produto do trabalho, que passa ao controle do capitalista; há uma crescente preocupação com a quantidade de produtos produzidos, quanto maior a produção maior o lucro do capitalista; mais do que nunca o capitalista controla o tempo do trabalho e o tempo ocioso dos trabalhadores, pois esses terão influência direta na produção; há a introdução da maquinaria no processo produtivo; a sociedade e o homem, em específico, tornam-se dependentes, há a plena dependência do trabalhador em relação ao capitalista; a divisão do trabalho se consolida e torna o princípio fundamental do sistema capitalista.

Para Enguita (1989), a expansão do capitalismo foi resultado de um processo prolongado, irregular e inacabado de lutas de classes, concorrência econômica e enfrentamentos políticos. E que somente foi conseguida, em função de cinco motivos: a privação dos trabalhadores, em especial dos camponeses, de quaisquer outras possibilidades de subsistências, a não ser a forma capitalista; o resultado de uma longa cadeia de conflitos globais, principalmente entre os patrões e os trabalhadores em seu ambiente de trabalho; uma profunda revolução cultural; uma sistemática política repressiva dirigida contra os que se negavam a aceitar as novas relações sociais; assegurar mecanismos institucionais (leis, decretos) para que cada novo indivíduo pudesse inserir-se nas novas relações de produção de forma não conflituosa, através da revitalização da escola.

Assim, pode-se supor que, a "degradação" do trabalho pelo capitalista ocorre em três fases distintas e complementares: a expropriação do trabalhador independente de seu trabalho, de sua terra; a conversão do mesmo em trabalhador assalariado; a divisão manufatureira do trabalho, com a subordinação real e completa do trabalhador ao capital. Contudo, a condição fundamental para que o capitalismo industrial pudesse se perpetuar era que os trabalhadores fossem despojados e separados de seu trabalho, tornando-se trabalhadores assalariados e sob o controle do capitalista.

A divisão do trabalho tem origem nos primórdios da sociedade humana, mas se materializa com o modo de produção manufatureiro e vai se consolidar em seu modo mais conhecido, o processo fabril, chegando a atingir todas as instâncias da sociedade. Desse modo a divisão do trabalho passa das instalações fabris para outras organizações sociais, como a família e a organização do trabalho escolar.

A divisão do trabalho ao mesmo tempo em que individualiza o trabalho, também o torna coletivo, na medida em que o produto final do trabalho será um esforço coletivo. No entanto, essa coletivização do trabalho só ser torna presente na prática e não na teoria.

A divisão do trabalho e conseqüente a especialização é necessária e fundamental para o capitalista manter o controle sobre o produto e o processo de produção, que acabam por consolidar seu poder e lucro, ou seja, a divisão do trabalho é o núcleo das relações hierárquicas de dominação.

Para Gorz (1980) a

divisão e o parcelamento das tarefas, a cisão entre trabalho intelectual e manual, a monopolização da ciência pelas elites, o gigantismo das instalações e a centralização dos processos que daí decorre - nada disso é necessário para uma produção eficaz. Em compensação, isso é necessário para que o capital possa perpetuar sua dominação. Para ele, qualquer organização do trabalho deve ser, indissoluvelmente, técnicas de produção e de dominação patronal sobre aqueles que produzem; pois a finalidade da produção capitalista nada mais é do que o 
aumento do capital em si; e tal finalidade, alheia aos trabalhadores, só pode ser realizada por eles, sob coerção (direta ou velada). (p. 6)

Portanto, a divisão capitalista do trabalho pode ser considerada a fonte de todas as alienações do homem.

Lili Kawamura (1990), afirma que historicamente a tecnologia e a educação estão baseadas na separação entre o saber e o fazer na divisão social do trabalho. Assim, a consolidação da divisão entre o saber e o fazer ocorre nos primórdios do sistema de produção capitalista, ou seja, a partir do momento em que os capitalistas se apropriarem da concepção e organização do processo produtivo, deixando para o trabalhador a função da execução consolidam a separação entre o fazer e o saber, entre a teoria e a prática.

Qual o papel desempenhado pela instituição escolar nesse momento histórico?

À escola coube a função de preparar as crianças e os jovens para o trabalho, e familiarizá-las às relações sociais do processo de produção capitalista. Ou seja, sua função era formar mão-de-obra qualificada para atender as necessidades do modelo de produção capitalista.

A escola ${ }^{3}$ nesse período está pautada nos princípios da sociedade capitalista, onde encontramos uma sociedade estratificada e dividida em setores sociais, esta mesma divisão justifica a criação de dois tipos de escolas. Uma destinada a atender aos filhos dos setores sociais mais abastadas, os detentores do capital; e uma outra, uma escola profissionalizante, destinada a oferecer instrução para os filhos dos trabalhadores assalariados.

Portanto, a escola é necessária para satisfazer os interesses do capitalista e as necessidades produtivas da sociedade. Intencionalmente ou não, a escola corrobora para a manutenção da lógica capitalista e da divisão do trabalho.

Entretanto em vários momentos históricos a escola é tida como instrumento de ascensão social, inclusive quando de sua criação na época da Revolução Francesa? Mas será que realmente a escola pode ser considera como instrumento de ascensão social dos homens? Pode-se dizer que, teoricamente sim, mas que na realidade isso só se verifica para uma minoria da população, quando ocorre.

A escola exerce aqui um duplo papel. Por um lado abre uma via, embora para a maioria seja mais aparente que real, através da qual é possível melhorar a posição de indivíduos e grupos dentro dos cursos de ação estabelecidos e aceitos e sem risco de desembocar em um conflito aberto. Fundamentalmente, permite aos grupos ocupacionais reforçar sua posição controlando as possibilidades de acesso ao mesmo, as quais são restringidas através da elevação das exigências em termos educacionais; e, sobretudo, permite aos indivíduos lutar pessoalmente para mudar de grupo, para aceder a outro situado em uma posição mais desejável. $\mathrm{Na}$ realidade, a escola é hoje o principal mecanismo de legitimação meritocrática de nossa sociedade, pois supõe-se que através dela tem lugar uma seleção objetiva dos mais capazes para o desempenho das funções mais relevantes, às quais se associam também recompensas mais elevadas. (Enguita,1989,p.192)

E complementa, afirmando que a própria

escola reproduz sob múltiplas formas a divisão do trabalho imperante na sociedade. A mais elementar destas formas, embora não a mais importante, é a sua própria divisão interna. (p.199-200)

Assim, a escola pública deveria corroborar, efetivamente, para que se transforme em um instrumento real de possibilidade de ascensão social dos homens numa sociedade divididas em setores sociais e com grandes desigualdades sociais. Desse modo, a escola pública pode ser considerada como um dos fatores fundamentais na consolidação de uma sociedade mais justa e igualitária, pois o papel social da instrução é o de atribuir condições para o princípio da igualdade entre os homens. Contudo, é importante destacar

\footnotetext{
${ }^{3}$ A idealização da escola pública surgiu na França, no século XVIII, em plena Revolução Francesa e foi o Iluminismo, enquanto ideologia e movimento intelectual, que fortaleceu a discussão em torno da criação da instrução pública.
} 
que a escola é a expressão da sociedade, mas não pode ser vista como transformadora da sociedade.

Com a criação, durante a Revolução Industrial, de dois modelos de escolas - uma destinada aos filhos do setores mais privilegiados e outra para os filhos dos trabalhadores - fica claramente evidenciada a divisão entre o trabalho manual (prática) do trabalho intelectual (teoria). A idéia da separação e da fragmentação cada vez maior entre teoria $e$ prática, entre saber e fazer que teve início com a divisão do trabalho nas instalações fabris irá se concretizar com a criação de dois modelos de escolas para atender as necessidades de setores sociais diferenciados da sociedade.

A partir do momento em que, ao final do século XIX a escola perde sua importância inicial, pois com o grande desenvolvimento tecnológico e a maior simplificação do trabalho nas instalações fabris, o capital apenas precisa, agora, da força de trabalho dos homens para operar as máquinas, portanto, a escola não é mais chamada para desenvolver habilidades especiais e complexas. Esse processo inviabilizou qualquer possibilidade de 0 trabalhador recuperar a unidade entre teoria e prática que detinha o artesão medieval, que pode ser chamado de trabalhador qualificado, pois possui o controle sobre o produto de seu trabalho e o controle sobre o processo produtivo.

\section{A introdução da maquinaria na fábrica}

A maquinaria, de acordo com Marx (1987), é o meio utilizado pelo capital para produzir mais-valia, é o "instrumental de trabalho". Ou seja, a maquinaria, nada mais é do que aquilo que hoje denominamos de máquinas, tão utilizadas não somente nas fábricas, mas também em todos os ramos e setores da sociedade moderna.

A introdução da maquinaria moderna nas indústrias exigirá um novo modelo de trabalhador, diferente daquele até então exigido. Não obstante, o que muitos imaginavam, o desenvolvimento e a introdução da maquinaria ao invés de exigir cada vez mais conhecimentos e habilidades dos trabalhadores, teve um efeito reverso, ou seja, além da degradação do trabalho e do trabalhador, há uma "degradação" da qualificação necessária para o exercício das funções nas unidades fabris.

$\mathrm{Na}$ realidade, a introdução da maquinaria nas unidades fabris apenas serviu para piorar ainda mais, as condições de trabalho e de alienação do trabalhador. Pois, observase que os trabalhadores tornam-se meros "objetos e instrumentos" que devem estar a serviço da maquinaria, e mais agravante do que isso, deveriam ser capazes e aptos para se adaptarem às especificações de produção da maquinaria.

Braverman (1977), define muito bem a situação vivida pelos trabalhadores dessa época, ao afirmar que

o notável desenvolvimento da maquinaria vem a ser, para a maioria da população trabalhadora, a fonte não de liberdade, mas de escravização, não a de domínio, mas de desamparo, e não do alargamento do horizonte do trabalho, mas do confinamento do trabalhador dentro de um círculo espesso de deveres servis no qual a máquina aparece como a encarnação da ciência e o trabalhador como pouco ou nada. (p. 168)

A acumulação de riquezas que o capital irá adquirir com a introdução da tecnologia e da maquinaria nas fábricas vai gerar diversas desigualdades sociais, até então inexistentes ou forjados. Ao mesmo tempo em que o capital vai acumulando mais riquezas com esse processo de transformação, vai haver um contingente maior de desempregados.

Poderíamos supor que, colocando a ciência a serviço da sociedade estes problemas pudessem ser solucionados, ou, ao menos minorados. Todavia, não é isto o que ocorre.

A questão da ciência posta a serviço dos interesses do capital, não é um fato novo, pois de acordo com Braverman (1977), 
contraste entre a revolução Industrial, que ocupou a metade do século XVIII e o primeiro terço do século XIX, e a revolução técnico-científica que começou nas últimas décadas do século XIX e que prossegue ainda. O papel da ciência na Revolução Industrial foi indiscutivelmente grande. Assim, em contraste com a prática moderna, a ciência não tomou sistematicamente a dianteira da indústria, mas freqüentemente ficou para trás das artes industriais e surgiu delas. (p. 138)

E complementa ainda, afirmando que a ciência - enquanto propriedade social -, juntamente com o trabalho, são os instrumentos mais eficazes de auxílio ao capital, para este possa atingir seus objetivos.

A principal importância da introdução da maquinaria para o processo produtivo, tendo em vista atingir os objetivos do capital são

desse ponto de vista, o elemento fundamental na evolução da maquinaria não é a dimensão, complexidade ou velocidade de operação, mas a maneira pela qual suas operações são controladas. (Braverman,1977,p.163)

Diante desses fatos, pode-se presumir que o desenvolvimento do modelo de produção capitalista e a conseqüente introdução da maquinaria nas fábricas propiciaram o aprofundamento do abismo existente entre o trabalhador e a máquina, devido exclusivamente, à aplicação dada pelo capital.

Para Marx (1987),

É incontestável que a maquinaria em si mesma não é responsável de serem os trabalhadores despojados dos meios de subsistência. Ela barateia e aumenta o produto no ramo de que se apodera e, de início, não modifica a quantidade de meios de subsistência produzidos em outros ramos. (p. 506)

Entretanto, continua afirmando que

este é o ponto nevrálgico da apologética econômica. Para ela, as contradições e antagonismos inseparáveis da aplicação capitalista da maquinaria não existem, simplesmente porque não decorrem da maquinaria, mas de sua aplicação capitalista. A maquinaria, como instrumental que é, encurta o tempo de trabalho, facilita o trabalho, é uma vitória do homem sobre as forças naturais, aumenta a riqueza dos que realmente produzem, mas com sua aplicação capitalista, gera resultados opostos: prolonga o tempo de trabalho, aumenta sua intensidade, escraviza o homem por meio das forças naturais, pauperiza os verdadeiros produtores. (p. 506)

Da mesma forma que Marx, também Braverman (1977), afirma que assim como na fábrica, não é nas máquinas que está o erro, mas nas condições do modo capitalista de produção sob as quais elas são utilizadas. (p. 239)

Diante do exposto e apresentado até o presente momento, podemos conjeturar que nossa hipótese de trabalho inicialmente proposta - de que a maquinaria em si, como instrumento auxiliar do progresso, é benéfica para a sociedade e para o trabalhador, no entanto, a aplicação dada pelo capitalista é que poderá ser prejudicial para os mesmos, em especial para o trabalhador e suas condições de trabalho -, é aceitável. Contudo, também devemos lembrar que, o dito "progresso" e seus benefícios, tais como - maior conforto, maior variedade de produtos para consumo e satisfação das necessidades humanas, enfim, a tão almejada melhoria das condições de vida -, apenas puderam ser sentidas e usufruídas por uma pequena parcela da população.

\section{Considerações finais}

Podemos supor que a Revolução Industrial e a introdução da maquinaria no processo produtivo, enquanto fundamental para a consolidação e fortalecimento do sistema de produção capitalista, tiveram como principais implicações para o trabalhador: a perda de exclusividade do trabalhador masculino como única força de trabalho disponível; o processo de divisão do trabalho; a simplificação e especialização do trabalho; a incorporação das mulheres e das crianças no processo produtivo; o aumento da força de trabalho no mercado de trabalho; os baixos salários pagos, em função da grande oferta de mão-de-obra disponível; a "degradação" do trabalho; o quadro de miséria material e moral dos trabalhadores. 
O princípio de propriedade é tido como fundamental para a independência dos homens, a partir do momento que o homem perde sua propriedade ele começa a ficar dependente do capitalista, que possui a propriedade. Esse princípio será o divisor entre 0 período pré-industrial e o período industrial.

O tão almejado "progresso" - termo que significa evolução, melhoria, desenvolvimento - conseqüente do sistema capitalista nunca esteve disponível para todas as pessoas em sua plenitude. Apenas algumas podiam e podem usufruir plenamente de seus benefícios, os detentores do capital, para as demais apenas alguns poucos benefícios são destinados.

Com o surgimento da sociedade industrial, pautada nos princípios do modelo de produção capitalista, o homem viu-se expropriado do produto de seu trabalho, do controle sobre os meios de produção e do seu saber. Processo este que deu-se através da divisão do trabalho e que reduziu o homem à sua capacidade de trabalho, a um mero instrumento do processo produtivo e "ajudante" das máquinas.

O desenvolvimento da divisão do trabalho, caracterizado em sua plenitude na fábrica moderna com o processo produtivo, desvinculou o trabalho teórico do trabalho prático, divisão esta que foi progressivamente tornando-se cada vez mais irrecuperável nesse tipo de sociedade. Aqui surge, uma questão importante de nossa sociedade, a dicotomia existente entre teoria $X$ prática, entre saber $X$ fazer.

Á escola cabe o papel fundamental, nesse momento, de proporcionar aos trabalhadores 0 acesso ao conhecimento, de modo que lhes permita compreender a sociedade capitalista e seu movimento, ou seja, em sua totalidade e não apenas parcialmente. Portanto, a superação da divisão do trabalho somente poderá ser atingida com o auxílio da escola e a apreensão da totalidade por parte dos membros da sociedade.

\section{Referências Bibliográficas}

BRAVERMAN, H. Trabalho e capital monopolista: a degradação do trabalho no século XX. Rio de Janeiro: Zahar, 1977.

ENGUITA, Mariano F. A face oculta da escola: educação e trabalho no capitalismo. Porto Alegre: Artes Médicas, 1989.

GORZ, André (Org.). Crítica da divisão do trabalho. São Paulo: Martins Fontes, 1980. HOBSBAWM, Eric J. Da Revolução Industrial Inglesa ao Imperialismo. 2ª edição. Rio de Janeiro: Forense, 1979.

KAWAMURA, Lili. Novas tecnologias e educação. São Paulo: Ática, 1990.

MARX, Karl. O capital: crítica da economia política. Livro Primeiro. Volume I. $11^{a}$ edição. São Paulo: DIFEL, 1987. 